\title{
"Naturalness" and Its Relation to Animal Welfare from an Ethological Perspective
}

\author{
Lorenz Gygax* (iD) and Edna Hillmann \\ Animal Husbandry, Albrecht Daniel Thaer-Institute of Agricultural and Horticultural Sciences, \\ Humboldt-Universität zu Berlin, Unter den Linden 6, 10115 Berlin, Germany; edna.hillmann@hu-berlin.de \\ * Correspondence: lorenz.gygax@hu-berlin.de; Tel.: +49-30-2093-6066
}

Received: 13 July 2018; Accepted: 31 August 2018; Published: 3 September 2018

\begin{abstract}
Here we view naturalness from the point of view of proximate behavioural control. The mechanisms of behaviour control have evolved in order that animals reach a specific goal after they have performed motivated behaviour. This goal was closely related to a function at the time when the mechanism evolved. Function and goal may be de-coupled in a novel environment such as artificial housing conditions. We argue that an animal that can perform the behaviour it wants and can reach the goals it likes can behave according to what is "in-its-nature" even under human influenced conditions. We illustrate this argument using abnormal sucking behaviour in calves and piglets as well as dehorning in cattle and goats. We conclude that a minimal welfare standard is ensured for animals that are given the opportunity to behave as is in-their-nature.
\end{abstract}

Keywords: ultimate; proximate; want; like; motivation; goal; function; sucking behaviour; de-horning

\section{Naturalness, the Ethologist's Perspective}

Yeates recently defined naturalness in animals as a state in which humans have not interfered [1] (p. 5, top). Though this definition may be correct from an etymological and philosophical standpoint, it has limited use for the assessment of animal welfare [1]. In addition, it excludes humans from being part of nature. It negates also recent ideas that see animals as much more active in their (behavioural) choices. Animals may not be as passively subjected to the pressures of their environment as has previously been thought [2]. Moreover, there are recent findings on the domestication process indicating that species actively sought the closeness to humans and in that sense domesticated themselves to some degree [3-5]. If that is the case, would we need to consider the behaviour of these animals as unnatural from the point of contact with humans and as more unnatural than other interactions they may have had with other (animal) species? Given these difficulties, we propose a different view on naturalness that takes the view that animals actively shape their fate. Moreover, this definition may be related more directly to the welfare of animals in the end. From an ethological perspective, it is possible to define naturalness as behaviour that is "in-the-nature" of a given animal subject. If a subject can perform this behaviour, some basic level of welfare is ensured, even in an environment that may look quite different from the wild habitat.

How does the behaviour in-the-nature of a subject come into existence? Tinbergen [6] was the first to note that there are different aspects that shape behaviour $[7,8]$. In an ultimate sense, each behaviour has a function, and animals that reach this function more efficiently, or more effectively have a higher evolutionary fitness. Evolutionary fitness is reflected by a larger number of offspring. These offspring carry the genetic basis for the given behaviour. Some epigenetic effects transferred from the mother may already modulate this basis. Starting from this (epi-)genetic foundation, a subject further develops throughout its own ontogeny, which includes individually learning and dealing with the specific environment that this subject encounters. Finally, an adult state is reached in which behaviour is 
controlled by a mature but still flexible proximate (neural) mechanism [9]. The ontogenetic process and the resulting behavioural control mechanism are seen as part of the proximate questions in respect to behaviour. Behavioural control ensures that the motivated and executed behaviour reaches (proximate) goals, which are related but not necessarily identical to their function [9-11]. It is sufficient that the goals were closely correlated with the function when the genetic basis of that behavioural process was laid down at the time when the control mechanism evolved.

With animals in human care (farm, companion, laboratory, and zoo animals), natural selection based on reaching the functions of behaviour no longer operates. Nevertheless, little seems to have changed throughout the process of artificial selection with respect to the general organisation of behaviour. In all domesticated species, the behavioural heritage of their wild ancestors remains largely visible, though e.g., the species' temperament has changed towards being more docile. For example, in all species that have been kept again in feral conditions, the behaviour that was performed was highly similar to that of their wild ancestors ([12]; pigs [13-16]; cattle [17,18]); chickens [19]. The genetic basis of behaviour has been conserved and therefore seems to be highly inert. One potential reason for this may be the complexity of the genetic basis of the behavioural control mechanisms or the interaction of this basis with the environment during development. Behavioural control is the major task that the brain executes, and with respect to the brain, novel theories suggest that the genetic basis provides information on how to build a brain (process) instead of providing a detailed blueprint for how the brain should be built (end product). As behavioural choice may even actively shape a large part of a species' niche, behaviour may persist if circumstances change (non-optimal behaviour) even in wild populations [2]. This may not be surprising when animals are viewed as entities "for" behaviour, i.e., beings that descend from ancestors that dealt reasonably well with their surroundings.

Animal affective states are considered highly relevant for animal welfare [20-22]. It is also highly likely that they are involved in behavioural control in at least three ways [9]. They help a subject to prioritise and select motivations and then execute what they "want", they signal whether a goal state has been reached (whether it is "liked") and, in the form of a specific mood state, modulate these wants and likes. In this sense, behavioural control is directly linked to affective states. These, in turn, are prominent in shaping an animal's emotional wellbeing.

With respect to naturalness from an ethological point of view, we could therefore say that a subject behaves naturally (that is, according to what is in-its-nature) whenever it can perform the behaviour that it wants (is motivated to perform) and can reach the corresponding goal states (it then likes what it achieved with its behaviour $[9,11])$. A natural-looking environment is not the only environment where an animal may follow its wants and reach its goals. If adequate stimuli are provided, even an artificial-looking environment may allow an animal to act on its wants and reach the according goal states (see Box 1, sucking behaviour). For example, given the right stimuli (such as feeder and drinker position and part of the pen adjacent to unfamiliar pigs, and/or with a wet floor) and objects (long-stemmed straw), pigs will separate an area for defaecation [23-25] and build a nest before farrowing [26]. Both these behaviours are likely to enhance welfare, the former will keep the pigs cleaner and the later will satisfy a strong inherent motivation. If the stimuli/objects are not provided this will restrict the welfare of the pigs. 
Box 1. Sucking behaviour in calves.

Mammalian infants are highly motivated to perform sucking behaviour (Figure 1). In the wild, sucking the udder of the dam and receiving milk is essential for survival. Is it possible to substitute the dam while allowing for oral behaviour "in the nature of a milk-dependent mammal"? We want to discuss two situations concerning farm animal species here. Dairy calves are usually separated from their dam right after birth, because the milk of the dam is seen as too valuable to be fed to the calves. The calves are then kept either singly or in peer groups. They are fed milk or milk replacer artificially, e.g., via an automatic milk feeder. This management practice often leads to cross-sucking, a redirected, abnormal oral behaviour, where calves suck the scrotum, udder, ears or snouts of peers. Offering large amounts of milk may reduce cross-sucking ([27,28], but see [29]), but providing calves contact to either the dam [30,31] or a foster cow [32] eliminates cross-sucking. We found that calves did not develop cross-sucking with only two times $15 \mathrm{~min}$ of daily contact [30].

For dairy calves, we can therefore conclude that a milk feeder ensures nutritional needs, but is not suitable in terms of allowing the sucking behaviour in-the-nature of a calf. Hunger seems to play a major role in triggering cross-sucking. Thus, allowing ad libitum milk may help to reach the goal of sucking at least to some extent. Moreover, sucking milk from an udder of either the dam or a foster cow allows the calves to reach the goal of this highly motivated behaviour fully. This goal is reached even if social contact time is limited to a minimum.

On the other hand, piglets are sometimes reared artificially when a sow gives birth to more piglets than she can suckle. Here, the surplus piglets are removed from the sow after the colostral phase and kept in pens with peers. In these pens, milk is provided in cups [33]. In such a system, piglets drink the milk without performing nutritive sucking. Since milk is provided ad libitum, nutritional needs are met fully. Nevertheless, the majority of such piglets develop belly-nosing, another redirected, abnormal oral behaviour. Providing piglets with dummies that allow non-nutritive sucking could reduce but not prevent belly-nosing [34]. In contrast to cross-sucking in calves, hunger thus seems to play only a minor role in belly-nosing of piglets. However, both cross-sucking and belly-nosing can seemingly only be reduced by allowing them to (artificially) suck milk. Oral behaviour as it is in-the-nature of a calf or a piglet involves sucking a "real" udder the characteristics of which cannot easily be substituted.

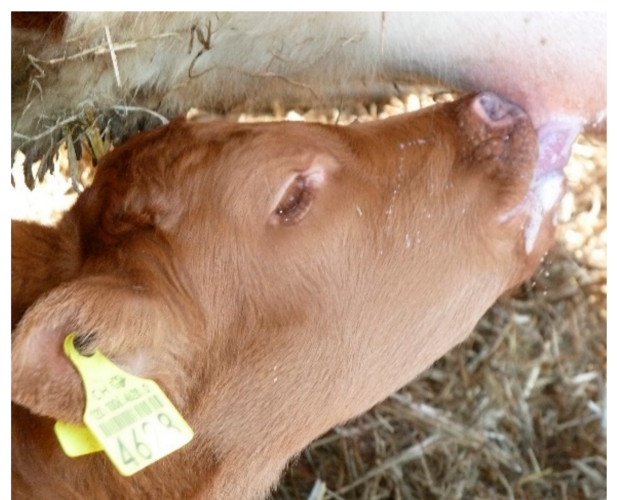

(a)

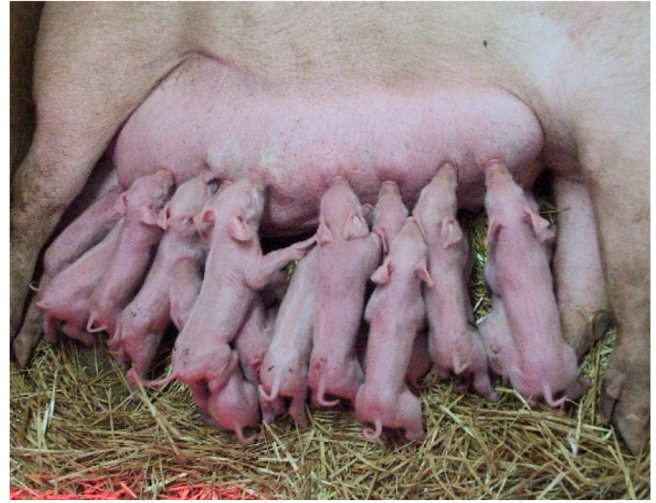

(c)

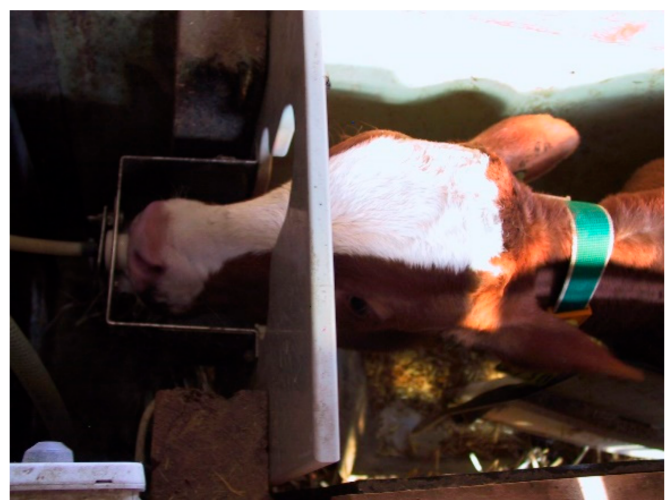

(b)

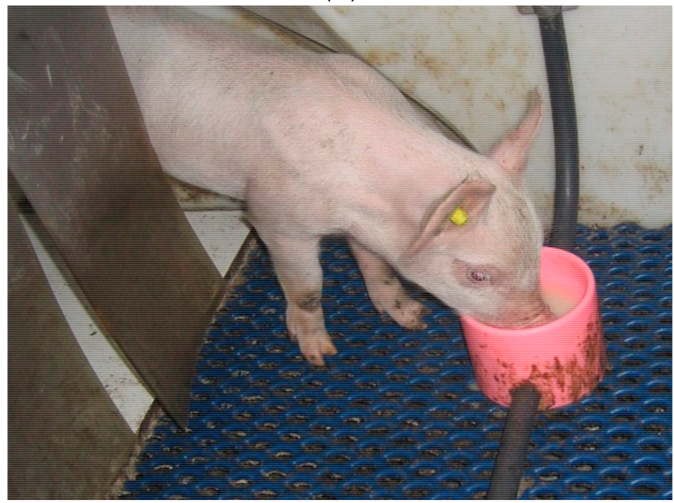

(d)

Figure 1. Milk feeding in calves $(\mathbf{a}, \mathbf{b})$ and piglets $(\mathbf{c}, \mathbf{d})$, either from the udder $(\mathbf{a}, \mathbf{c})$ or artificially $(\mathbf{b}, \mathbf{d})$.

What a subject wants is the integrative result of internal and external stimuli and states as well as their affective assessment. If internal aspects dominate, we may also speak of behavioural needs [35]. 
Most wants will be influenced to some degree by both internal and external states. However, internal states will be more important for some wants (e.g., hunger) than for others (e.g., predator avoidance), where external stimuli become more important. If an animal can follow its wants and achieve the corresponding goals, a large share of the emotional aspects of well-being is likely to be assured. It may be necessary to differentiate between fleeting wants that may be irrelevant in the long-term (e.g., a pig trying to catch a mouse that happens to cross its pen) and persistent or recurring wants that can only be satisfied by reaching a specific goal state (e.g., nest-building in pigs for which they are willing to invest quite some effort). The latter wants can only properly be dealt with by reaching the corresponding goal state, which then become necessary. Given this view that wants should be fulfilled and goals liked, it may be difficult to provide an animal subject with continuous positive emotional states. Where emotions occur in proximate control, they do not function to provide continuous positive states. If that was the case, we would no longer want anything nor like what we reached. Therefore, behaving according to a subject's nature will provide a solid foundation for welfare and possibly the best welfare we can get (for ourselves and the animals in our care).

\section{Assessment of Naturalness}

To quantifying naturalness, Yeates proposed to find a population unaffected by human beings that is as similar as possible to the population for which naturalness is to be assessed [1]. He then suggests that the population in question shows natural behaviour if their behaviour is within the range of what can be observed in the unaffected counterpart. This process is prone to several difficulties. This would imply that the unaffected population was observed in the broadest variability of circumstances possible to ensure that all natural behaviour was covered. For example, feral populations of pigs would need to be observed in woodlands, open shrub environments, mountainous planes, and possibly even on Caribbean beaches. Still, one would never know if the chosen circumstances were broad enough in order to ensure that everything else that might be observed in the affected population could be considered "unnatural". Moreover, according to this premise, naturalness can be accepted only if a 1:1 snapshot of the unaffected population is shown by the affected population. In respect to quantitative comparisons, Yeates remains rather vague in that no specific methods are proposed regarding how any potential difference should be assessed or how cut-offs can be designed to separate non-natural from natural behaviour. He suggests considering which behaviours occur for how long and in which sequence. This spans a highly multi-dimensional space in which natural behaviour is described. This may well reflect how behaviour is structured, but there may then easily be a discrepancy between a human-influenced and a natural population in certain (few) dimensions, for example, the human-influenced population may not differ in the ethogram (the behaviours that occur) but the behavioural budget may be very different. How would one assess such a situation? In the end, such a comparison would be very hard to evaluate given the different dimensions and levels on which behaviour can be measured (and then compared).

In addition, such a view is inconsistent with the existing flexibility of behaviour ("phenotypic plasticity"). For example, if, in human care, there is a behaviour to which an animal subject is no longer motivated, such as predator avoidance, the subject is not directly affected by the absence of that behaviour. Another such example is likely to concern sickness [11]. Although sickness behaviour can be considered natural, a motivation for sickness behaviour is highly unlikely to be missed ("needed") in the absence of disease. Therefore, health as an important component of animal welfare does not oppose natural behaviour in any way. It is also plausible that a goal may be more easily attained in human care because the time constraints for different behaviours may be eased. In that case, a motivated behaviour would only need to be shown for a much shorter time to reach the goal state. There may still be an ethical question whether we should allow a specific behaviour to disappear in human care, but it seems difficult to argue that a subject directly suffers by the absence of a want that never comes up.

Given this somewhat less rigid view on how behaviour must look in a population with human contact, we would need to assess the wants and likes of an animal subject to assess whether it behaves 
according to what is in-its-nature. This is, admittedly, also no simple endeavour. For example, we may only know about those wants that we investigate and for which we provide an opportunity [36]. If we do not ask the right questions, some wants may go unobserved. On the other hand, some wants may only occur if we ask about them and might not occur at all if not asked about, such as predator avoidance that may only occur if a predator or predator cues are encountered. In addition, super-stimuli that have not or only rarely been encountered in the evolutionary past may not have effective goal states (such as consuming sugar, the self-application of drugs, or wheel running in rodents [36]). Whether such super-stimuli could even enhance welfare beyond the point as seen under natural conditions is likely to depend on the specific circumstances. Whereas this seems highly unlikely for consuming sugar or self-applying drugs, the case may be less clear for wheel running and would need further investigation. Wants may also differ largely depending on context and between individuals. Moreover, not all wants may be easily captured based on observable behaviour. Animals may also strive for and value meta-stimuli such as increasing knowledge (find "truth"), having choice, being able to learn, reaching a goal only after investing effort, managing what happens ("control"), or choosing among the promotion and prevention of risks [37]. Nevertheless, we concur with Yeates [1] that an attempt at tackling these sorts of questions is necessary. It is also worthwhile because with every single attempt to address these questions, the species that is investigated will be slightly better understood [10].

Though we very much doubt that an organism such as "lickens" can ever be produced due to the complexity of the genetic basis of behavioural control mechanisms (and we agree that producing such organisms would be highly questionable with respect to ethics $[38,39])$, they provide an interesting thought experiment [1]. Lickens are genetically modified chickens that have no legs, beaks or feathers. Whereas in Yeates view they are not natural because their behaviour deviates considerably from their wild counterparts, the red jungle fowl, we can still ask whether these lickens behave according to what is in-their-nature. From the ethologist's point of view, whether these lickens could behave according to their nature would depend on whether their behavioural control mechanisms were modified along with their anatomy. If they no longer had motivations for "pecking, flying, dustbathing, or laying eggs" they could be considered to behave according to their nature. If these motivations were still present (the behavioural control mechanisms unchanged), lickens would present a species with the most serious restriction imaginable in behaving according to their nature because they would have motivations for behaviour that they cannot anatomically execute. This species would also illuminate the difficulty in investigating their wants and likes. How could we find out about these wants and likes when the actions required can no longer be performed? However, we may influence the ability to perform a behaviour in farm animal species in much more subtle ways. For example, we may ask how much we interfere with how cattle behave if they are de-horned (or genetically hornless) and we can ask whether these cattle can still behave according to their nature (Box 2).

We fully agree with many of Yeates' conclusions [1]. Specifically, the occurrence of unnatural (abnormal) behaviour is likely to indicate a problem in the flexibility of behaviour control and is a warning sign with respect to behaving in-ones-nature and therefore with respect to animal welfare. However, even here the definition of unnatural behaviour may only be clear in extreme cases such as highly repetitive (stereotypic) behaviour. A more subtle behaviour that has been considered unnatural is cross-sucking in calves. Here, we can ask what goals need to be reachable for the calves such that they do not cross-suck, which may indicate that they can more closely behave according what is in-their-nature (Box 1). In any case, abnormal behaviour is also the result of a given behavioural mechanism. In this sense, it reflects "natural" behaviour under the given (artificial housing) conditions. Yet, with such a broad view of the term "natural", all behaviour would need to be considered natural and therefore, "naturalness" would become meaningless as an argument in the discussion of welfare. 
Box 2. De-horning cattle and goats.

Cattle (Bos taurus) belong to the taxon bovidae. The common trait of this taxon is a pair of postorbital horns. Horns, in contrast to antlers, consist of a bony core and a keratinized sheath, and cannot be shed as male deer do with the antlers. The ultimate functions of horns have been discussed by several authors (reviewed in [40]); there is evidence for horns serving thermoregulation as well as visual communication. Here, we focus on visual communication. Horns, as an "extension" of the head are likely to emphasise visual signals, e.g., threats that may lead to displacements (Figure 2). In addition, bovid animals may learn that horns hurt and thus avoid physical contact with a horned herd member. Since horned cows have been found to have larger individual distances ([41]; but for goats see [42]) compared to hornless individuals, and to avoid injurious accidents both between animals and with humans, most famers prefer keeping hornless cattle/goats. Disbudding or breeding are options that lead to hornless bovids, both representing obvious interventions by humans. Despite the fact that hornless animals do occur naturally in wild populations, this does not necessarily mean that these animals are not impaired (inevitably, not all the individuals in a population have maximal fitness). From an ethical point of view, one might prefer breeding genetically hornless subjects over disbudding calves or kids, since this a painful procedure. Nevertheless, when we think of the licken example, one might ask whether it is justified to breed away an organ that is part of the naturalness of a species/population. In contrast to a licken, a hornless cow or goat is still able to perform all behaviours that it would perform with horns and may well be motivated to do so. However, the goal of these behaviours might not be achieved as easily without horns, e.g., a subordinate herd member would not retreat in response to a threat. Thus, agonistic interactions may be exaggerated, and social hierarchy within a herd may become less stable [41]. Does this affect their emotional wellbeing? From an ethologist's perspective, we argue that the social behaviour of a hornless bovid might be "as it is in-its-nature" as long as the subject can perform the behaviour it is motivated to (which is possible without horns), and the goal can be achieved (i.e., individual distance is granted or access to a resource is given).
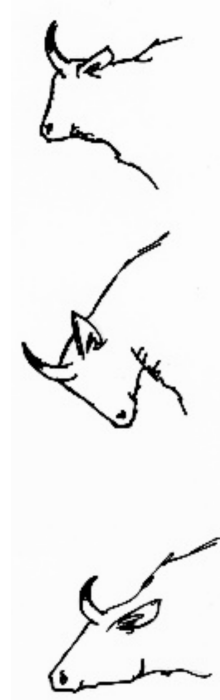
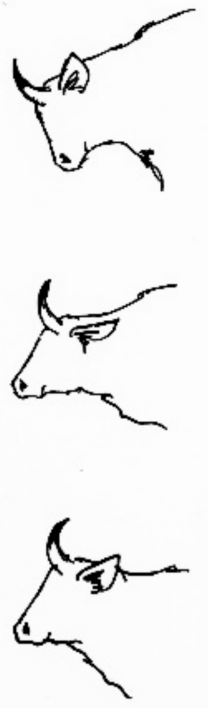
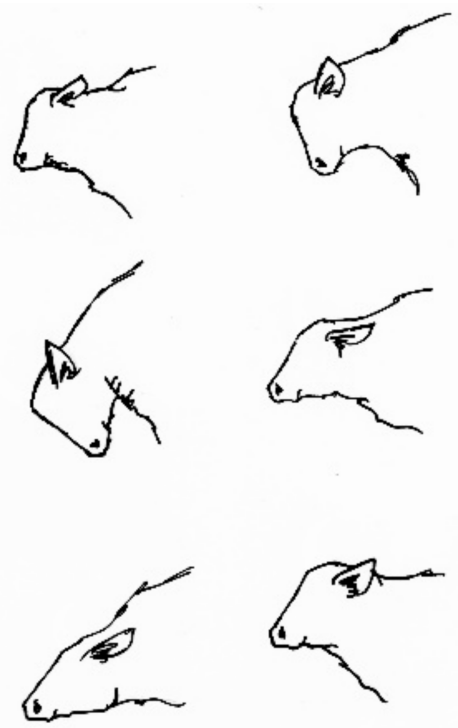

Figure 2. Horns emphasize visual display in cows. Adapted from [43], original courtesy of J. Probst.

It is more difficult to define how natural behaviour can be ensured. First, good health is the basis for being able to behave and therefore for natural behaviour. Additionally, if animals can follow their persistent or recurring wants and reach their goals, the integrity of their behaviour may be ensured in a way that is in-their-nature. This may eventually ensure a basic amount of welfare.

\section{Conclusions}

Behaving in a way that corresponds to what is in an animal's nature may be viewed as a pre-requisite for good welfare comparable with an individual's health. Natural behaviour in this sense involves reaching adequate goal states for all persistent or recurring wants that arise in a given environment. A full description of natural behaviour specifically in captivity is a convoluted long-term project piecing together information of what animals want and like. 
Author Contributions: Writing-Original Draft Preparation, L.G., E.H.; Writing-Review \& Editing, L.G., E.H.

Funding: We acknowledge support by the German Research Foundation (DFG) and the Open Access Publication Fund of Humboldt-Universität zu Berlin.

Acknowledgments: We would like to thank two anonymous reviewers for their constructive criticism.

Conflicts of Interest: The authors declare no conflict of interest.

\section{References}

1. Yeates, J. Naturalness and animal welfare. Animals 2018, 8, 53. [CrossRef] [PubMed]

2. Diogo, R. Evolution Driven by Organismal Behaviour-A Unifying View of Life, Function, Form, Mismatches, and Trends; Springer International Publishing AG: Cham, Switzerland, 2017; pp. 1-252.

3. Budyansky, S. The Covenant of the Wild: Why Animals Chose Domestication; William Morrow and Co. Inc.: New York, NY, USA, 1992.

4. Marshall, F.B.; Dobney, K.; Denham, T.; Capriles, J.M. Breeding and gene flow in animal domestication. PNAS 2014, 111, 6153-6158. [CrossRef] [PubMed]

5. Geiger, M.; Sánchez-Villagra, M.R.; Lindholm, A.K. A longitudinal study of phenotypic changes in early domestication of house mice. R. Soc. Open Sci. 2018, 5, 172099. [CrossRef] [PubMed]

6. Tinbergen, N. On aims and methods of ethology. Zeitschr. Tierpsychol. 1963, 20, 410-433. [CrossRef]

7. Bateson, P.; Laland, K.N. Tinbergen's four questions: An appreciation and an update. TREE 2013, 28, 712-718. [CrossRef] [PubMed]

8. Dawkins, M.S. Tribute to Tinbergen: Questions and how to answer them. Ethology 2014, 120, 120-122. [CrossRef]

9. Gygax, L. Wanting, liking and welfare: The role of affective states in proximate control of behaviour in vertebrates. Ethology 2017, 123, 689-704. [CrossRef]

10. Wechsler, B. Normal behaviour as a basis for animal welfare assessment. Anim. Welf. 2007, 16, 107-110.

11. Špinka, M. How important is natural behaviour in animal farming systems? Appl. Anim. Behav. Sci. 2006, 100, 117-128. [CrossRef]

12. Price, E.O. Behavioural genetics and the process of animal domestication. In Genetics and the Behaviour of Domestic Animals; Grandin, T., Ed.; Academic Press: San Diego, CA, USA, 1997; pp. 31-65.

13. Jensen, P. Observations on the maternal-behaviour of free-ranging domestic pigs. Appl. Anim. Behav. Sci. 1986, 16, 131-142. [CrossRef]

14. Stolba, A.; Woodgush, D.G.M. The behavior of pigs in a semi-natural environment. Anim. Prod. 1989, 48, 419-425. [CrossRef]

15. Woodgush, D.G.M.; Jensen, P.; Algers, B. Behavior of pigs in a novel seminatural environment. Biol. Behav. 1990, 15, 62-73.

16. Jensen, P.; Vestergaard, K.; Algers, B. Nestbuilding in free-ranging domestic sows. Appl. Anim. Behav. Sci. 1993, 38, 245-255. [CrossRef]

17. Hall, S.J.G. Chillingham cattle: Dominance and affinities and access to supplementary food. Ethology 1986, 71, 201-215. [CrossRef]

18. Lazo, A. Social segregation and the maintenance of social stability in a feral cattle population. Anim. Behav. 1994, 48, 1133-1141. [CrossRef]

19. Duncan, I.J.H.; Savory, C.J.; Wood-Gush, D.G.M. Observations on the reproductive behaviour of domestic fowl in the wild. Appl. Anim. Ethol. 1978, 4, 29-42. [CrossRef]

20. Boissy, A.; Manteuffel, G.; Jensen, M.B.; Oppermann Moe, R.; Spruijt, B.; Keeling, L.J.; Winckler, C.; Forkman, B.; Dimitrov, I.; Langbein, J.; et al. Assessment of positive emotions in animals to improve their welfare. Phys. Behav. 2007, 92, 375-397. [CrossRef] [PubMed]

21. Mendl, M.; Burman, O.H.P.; Paul, E.S. An integrative and functional framework for the study of animal emotion and mood. Proc. R. Soc. B 2010, 277, 2895-2904. [CrossRef] [PubMed]

22. Paul, E.S.; Mendl, M.T. Animal emotion: Descriptive and prescriptive definitions and their implications for a comparative perspective. Appl. Anim. Behav. Sci. 2018, 205, 202-209. [CrossRef] [PubMed]

23. Andersen, H.M.-L.; Pedersen, L.J. The effect of feed trough position on choice of defecation area in farrowing pens by loose sows. Appl. Anim. Behav. Sci. 2011, 131, 48-52. [CrossRef] 
24. Wang, Y.; Li, D.P.; Shen, X.; Shi, Z.X. Effects of inductive methods on dunging behavior of weaning pigs in slatted floor pens. Int. J. Agric. Biol. Eng. 2016, 9, 192-198.

25. Ocepek, M.; Goold, C.M.; Busančić, M.; Aarnink, A.J.A. Drinker position influences the cleanness of the lying area of pigs in a welfare-friendly housing facility. Appl. Anim. Behav. Sci. 2018, 198, 44-51. [CrossRef]

26. Arey, D.S. Straw and food as reinforcers for prepartal sows. Appl. Anim. Behav. Sci. 1992, 33, 217-226. [CrossRef]

27. Hillmann, E.; Johns, J.; Wagner, K.; Waiblinger, S.; Barth, K. Saugverhalten und Festfutteraufnahme muttergebunden aufgezogener Kälber. Anim. Nutri. 2011, 34, 115-117.

28. Uys, J.L.; Lourens, D.C.; Thompson, P.N. The effect of unrestricted milk feeding on the growth and health of Jersey calves. J. S. Afr. Vet. Assoc. 2011, 82, 47-52. [CrossRef] [PubMed]

29. De Passillé, A.M.; Borderas, F.; Rushen, J. Cross-sucking by dairy calves may become a habit or reflect characteristics of individual calves more than milk allowance or weaning. Appl. Anim. Behav. Sci. 2011, 133, 137-143. [CrossRef]

30. Roth, B.A.; Barth, K.; Gygax, L.; Hillmann, E. Influence of artificial vs. mother-bonded rearing on sucking behaviour, health and weight gain in calves. Appl. Anim. Behav. Sci. 2009, 119, 143-150. [CrossRef]

31. Lidfors, L.M.; Jung, J.; de Passille, A.M. Changes in suckling behaviour of dairy calves nursed by their dam during the first month post partum. Appl. Anim. Behav. Sci. 2010, 128, 23-29. [CrossRef]

32. Margerison, J.K.; Preston, T.R.; Berry, N.; Philipps, C.J.C. Cross-sucking and other oral behaviours in calves, and their relation to cow suckling and food provision. Appl. Anim. Behav. Sci. 2003, 80, 277-286. [CrossRef]

33. Rzezniczek, M.; Gygax, L.; Wechsler, B.; Weber, R. Comparison of the behaviour of piglets raised in an artificial rearing system or reared by the sow. Appl. Anim. Behav. Sci. 2015, 165, 57-65. [CrossRef]

34. Frei, D.; Würbel, H.; Wechsler, B.; Gygax, L.; Burla, J.B.; Weber, R. Can body nosing in artificially reared piglets be reduced by sucking and massaging dummies? Appl. Anim. Behav. Sci. 2018, 202, 20-27. [CrossRef]

35. Jensen, P.; Toates, F.M. Who needs behavioral needs? Motivation aspects of the needs of animals. Appl. Anim. Behav. Sci. 1993, 37, 161-181. [CrossRef]

36. Franks, B. What do animals want? Anim. Welf. 2018, in press.

37. Cornwell, J.F.M.; Franks, B.; Higgins, E.T. Truth, control, and value motivations: The "what", "how", and "why" of approach and avoidance. Front. Syst. Neurosci. 2014, 8, 194. [CrossRef] [PubMed]

38. Schmidt, K. Integrität und genetische Veränderung von Nutztieren. J. Verbraucherschutz Lebensmittelsicherheit 2009, 4, 399-406. [CrossRef]

39. Sandøe, P.; Hocking, P.M.; Forkman, B.; Haldane, K.; Kristensen, H.H.; Palmer, C. The blind hens' challenge: Does it undermine the view that only welfare matters in our dealings with animals? Environ. Values 2014, 23, 727-742. [CrossRef]

40. Kiltie, R.A. Evolution and function of horns and hornlike organs in female ungulates. Biol. J. Linn. Soc. 1985, 24, 299-320. [CrossRef]

41. Knierim, U.; Irrgang, N.; Roth, B.A. To be or not to be horned-Consequences in cattle. Livest. Sci. 2015, 179, 29-37. [CrossRef]

42. Aschwanden, J.; Gygax, L.; Wechsler, B.; Keil, N.M. Social distances of goats at the feeding rack: Influence of the quality of social bonds, rank differences, grouping age and presence of horns. Appl. Anim. Behav. Sci. 2008, 114, 116-131. [CrossRef]

43. Probst, J. Spengler Neff Erfolgreiches Rinderhandling; Forschungsinstitut für biologischen Landbau FiBL: Frick, Switzerland, 2014; pp. 1-28.

(C) 2018 by the authors. Licensee MDPI, Basel, Switzerland. This article is an open access article distributed under the terms and conditions of the Creative Commons Attribution (CC BY) license (http://creativecommons.org/licenses/by/4.0/). 